\title{
The Story as a Palliative for the Loss of Learning in a Specific Audience: The Case of Visually Impaired Students
}

\author{
Houssem Guedich $^{1 *}$, Mohamed Msalmi ${ }^{2}$, Ayman Guemri ${ }^{3,4}$, Olfa Tounsi ${ }^{5}$, Mourad Bahloul ${ }^{6}$ \\ ${ }^{1}$ Faculty of Humanities and Social Sciences of Tunis (FSHST), University of Tunis- Tunisia \\ ${ }^{2}$ FLSHS-LAD University of Sfax-Tunisia \\ ${ }^{3}$ Higher Institute of Sport and Physical Education of Gafsa, University of Gafsa, Tunisia \\ ${ }^{4}$ Group for the Study of Development and Social Environment (GEDES), Sfax, Tunisia \\ ${ }^{5}$ ECOTIDI UR 16ES10, Higher Institute of Education and Continuing Training (Virtual University), Tunis, Tunisia \\ ${ }^{6}$ Higher institute of business administration, University of Sfax, Tunisia
}

DOI: $\underline{\text { 10.36348/jaep.2022.v06i01.003 }}$ | Received: 14.12 .2021 | Accepted: 16.01 .2022 | Published: 28.01 .2022

*Corresponding author: Houssem Guedich

Faculty of Humanities and Social Sciences of Tunis (FSHST), University of Tunis- Tunisia

\section{Abstract}

This study is interested in the question of learning scientific knowledge related mainly to environmental education in an informal education setting through a sample composed of visually impaired students (14 students), belonging to a Club of environmental education at the ATEEA headquarters, in the region of Sfax. Six stories and six knowledge / understanding tests on various environmental themes were administered during six sessions. Each session was spread over 3 moments, namely a pretest evaluating initial knowledge; recitation of the story (by the storytelling technique in the experimental group $(\mathrm{N}=7)$ and by the reading technique in the control group $(\mathrm{N}=7)$ and finally a post-test involving the same concepts mentioned in the preliminary test. Analysis of the mean scores between pre-tests and post-tests shows a significant improvement in correct answers for students in both groups. On the other hand, the students of the storytelling group showed a significantly higher performance than that of the students of the reading group at the level of the correct answers to the causal propositions. Thus, the storytelling methods made it possible to compensate for the loss of learning leading to the understanding of the different narrative texts recited in the experimental group. The study recommended using stories and the practice of storytelling in school and out-of-school context (clubs, sequences recorded on educational platforms, etc.) in order to remedy the learning loss for visually impaired students in a particular way and for other students in general.

Keywords: Storytelling, story reading, Comprehension, knowledge, visually impaired, Learning loss, Teaching practices.

Copyright (C) 2022 The Author(s): This is an open-access article distributed under the terms of the Creative Commons Attribution 4.0 International License (CC BY-NC 4.0) which permits unrestricted use, distribution, and reproduction in any medium for non-commercial use provided the original author and source are credited.

\section{INTRODUCTION}

Today, the world is experiencing a learning crisis, with more than 250 million children without access to education and more than half of children aged 10 in low- and middle-income countries who can neither read nor understand a simple text $\left[{ }^{1}\right]$. In addition, school closures caused by the COVID-19 pandemic have increased the scale of this crisis and caused serious learning losses in several countries around the world.

\footnotetext{
1 https://www.globalpartnership.org/en/what-we-
}

With the unexpected closures of schools, due to the COVID-19 pandemic millions of students around the world are affected (UNESCO, 2020). The attention of educational researchers is increasingly focused on what is known as "learning loss", further endorsing the apprehension of students, teachers and parents. To improve learning outcomes, countries need (among other things) reliable data on learning, which requires strong learning assessment systems. Unfortunately, this remains a major challenge in many partner countries.

With the urgent need to proceed with a nonvisual didactic tool for blind and visually impaired students and in order to overcome certain difficulties in these learning subjects (such as boredom in class, difficulty in being attentive, demotivation and loss of all 
Houssem Guedich et al., J Adv Educ Philos, Jan, 2022; 6(1): 12-23

sense of curiosity ...) and in order to compensate for the loss of learning in these visually impaired, we opted after reflection for a literary genre containing rich and varied scientific information and knowledge usually foreign to the culture of children at primary level namely scientific tales. The problem posed by this study consists of questioning the way in which we could proceed in order to be able to convey this environmental culture and simultaneously optimize the understanding of the different narrative texts proposed. To do this, two different teaching practices were used to convey the content of our stories namely; the teaching practice of reading and the teaching practice of storytelling. After presenting the methodology of the study, we present our results and discuss, the effect of reciting stories (by reading and by storytelling) on the acquisition of immediate knowledge of visually impaired students and the effects of teaching practice of storytelling on the mean of correct answers to causal propositions.

\section{Theoretical and conceptual framework}

This first part of this article is devoted to clarifying some of the key concepts used in this study. We begin by putting the loss of learning into perspective before devoting ourselves to the structures and mechanisms involved in the understanding of the text, the scientific tale and its place in popular literature and finally the teaching practice of reading and that of storytelling.

\section{1. Loss of learning}

In its most basic definition, the notion of "learning loss" indicates the loss of prior learning, with the inevitable effect that, when learners return to class, they experience less than before. However, this concept does not cover the same meaning in various studies on the question.

Generally speaking, studies of learning loss fall into four categories: studies of the consequences of absenteeism on student learning; those focusing on the consequences of the closure of schools due to bad weather conditions, those focusing on the consequences of summer holidays on student learning and finally research focused on the effects of natural disasters on learning students. Admittedly, the closure of schools following the Coronavirus pandemic resulted in significant learning losses and are now confirmed by real data $\left[{ }^{2}\right]$. However, the learning loss predates the pandemic context and seems to be attributable in the first place to the recurrent absences of the students for various reasons.

Of particular note here are students from lowincome households and children with disabilities. The

2 https://fr.unesco.org/news/pertes-dappartementcausees-fermetures-decoles-liees-au-covid-19-risquentdappauvrir-toute negative impact on learning disproportionately affects the most marginalized or vulnerable such as the visually impaired in our study sample. Learning losses are also greater for students of lower socioeconomic status in countries like Tunisia, especially for students from the interior of the country and belonging to disadvantaged rural or urban backgrounds.

On the basis of the reasons mentioned above, the phenomenon of "loss of learning" in summer is possibly, and rightly so, better known under the name of the "summer learning effect", described as stagnating or declining results during the summer (Meyer, Meissel $\&$ McNaughton, 2017, p. 232). Another crucial point to consider about these studies is that research on the appreciation of the loss of learning during the summer or on the curriculum assessment $\left[{ }^{3}\right]$ aims to reduce them by focusing usually on the results obtained in two school subjects, in this case reading and mathematics (Fitzpatrick, 2018) in (Cardinal, 2020) $\left[{ }^{4}\right]$.

Regarding natural disasters, these lead to the continued closure of many schools, which is why some articles have taken up the conclusions of these studies in an attempt to anticipate the consequences of the COVID-19 pandemic on student learning. An essential point to remember is that students affected by a natural disaster often have to face a whole series of consequences which result from it. Therefore, it is possible that their house was completely destroyed, that they had to be empty, sometimes without their families and in places very different from where they lived. In these circumstances, it is obvious that the consequences on learning will not be simply due to the closure of their school. In the Arab world, certain studies have been carried out, including the report by Gibran (2021) in which the author returned to the tripartite mission (UNESCO, UNICEF and the World Bank) to deal with learning losses. among students because of the wars in certain regions such as Palestine and Iraq or even following the closures of schools during the 2020 containment after the outbreak of the epidemic in the world. Other researchers like Abdelwadoud (2020), Issa (2020) and Romhi (2021) have focused on the causes and consequences of learning loss. On the one hand, the phenomenon in question can be attributed to the learner himself, to his family, to the education system, to society, to the economic choice of the State and finally to emergencies such as war, climatic conditions. or even epidemics. On the other hand, prejudices can affect the student (repeating a year, dropping out of school, loss

\footnotetext{
${ }^{3}$ A curriculum is indeed a program or a plan of studies, but considered in its systemic globality, in its didactic coherence, in its chronological continuity, that is to say according to the order of progressivity of situations and learning activities to which it is supposed to give rise.

${ }^{4}$ Cardinal, J. (2020), Learning loss: what the research really says. International Baccalaureate Organization, UK.
} 
Houssem Guedich et al., J Adv Educ Philos, Jan, 2022; 6(1): 12-23

of confidence in the education system, etc.) as well as the State (the waste of resources, the increase in unemployment and delinquency, the decrease in the rate of economic growth, etc.).

\section{2. Structures and mechanisms involved in understanding the text}

It goes without saying that comprehension is not an easy and simple activity for young students, especially if they are learners with difficulties (presenting cognitive disorders). The act of understanding, like the act of knowing, is a process, not a product, as Jérôme Bruner points out, which requires a major effort on the part of the reader. In this perspective, Umberto Ecco (1985) states in this sense that the text is a "lazy machine which requires the reader relentless cooperative work to fill the spaces left unsaid or already said in white ".

In view of this complex and multifaceted aspect, understanding requires fundamental cognitive knowledge and skills on the part of the reader. Much research has attempted to synthesize the consensus relating to the structures and cognitive mechanisms involved in this activity. We refer, in this article, to the diagram of Bianco (2016).

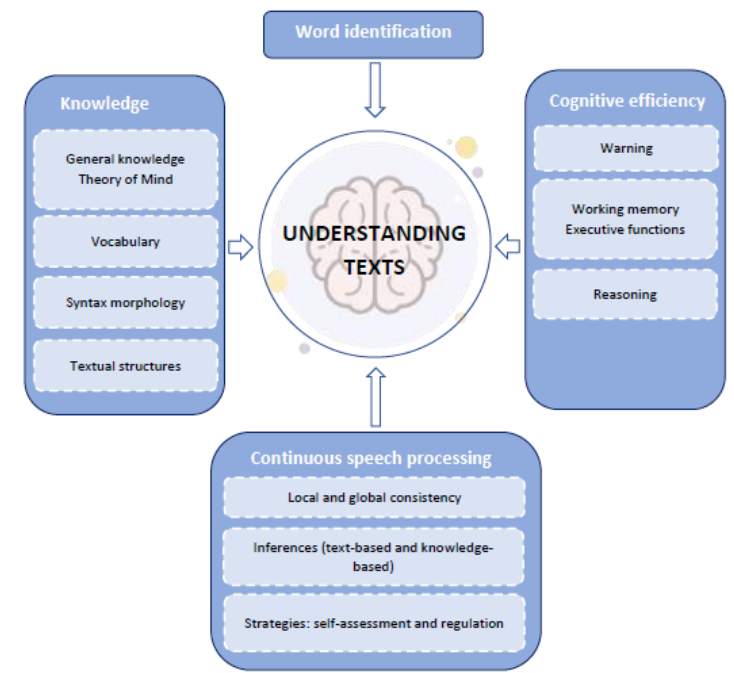

Figure 1: Structures and cognitive mechanisms involved in the understanding of texts Source: Bianco (2016) in Girardet (2018) [ $\left.{ }^{5}\right]$

As we note from this diagram, comprehension requires on the part of the reader four main categories of skills which are often called upon simultaneously: the ability to identify words, the knowledge stored in memory, the general cognitive efficiency of individuals

\footnotetext{
5 Girardet, P. (2018). The construction of the comprehension of narrative texts by pupils with cognitive disorders: research carried out within localized units for inclusive education, University of
} Lyon. and skills specific to the processing of continuous speech.

The first is the most important task because it constitutes the main stumbling block especially among beginner readers and requires the mental discovery of the alphabetic principle and then the mastery of regular graphophonological correspondences. The decoding must be fast and fluid to allow the release of the other resources necessary for the implementation of the other skills required for comprehension.

Subsequently, the reader must seek his knowledge, those relating to language, the text and those concerning the world. With regard to knowledge about language and text, also called microstructures and macrostructures, we can cite the morphosyntactic organization of texts which have their own organization at the level of the sentences that compose them but especially at the textual typology level. A narrative text is not organized in the same way as a scientific text for example. Indeed, if the story is organized around the characters, their objectives and their intentions, the documentary text is structured by other components such as comparisons, enumerations, the exposure of causal chains or reasoning.

The reader should, therefore, recognize the markers of these organizations. Lexical knowledge has a great influence on comprehension. Those who read little will have a low lexical capital and this will have an impact on comprehension. The vocabulary also depends on the type of text studied. Storytelling, for example, has more familiar vocabulary. Knowledge about the world is crucial in understanding. Indeed, it has been shown that those who have richer knowledge on a subject addressed in a text, understand the information better.

In reading narrative texts, the reader must appeal to knowledge relating to interpersonal relationships, emotions, everyday situations for a better understanding. Then, it is a question of the skills which concern the treatment of continuous speech which require above all the understanding of the explicit indices, in other words the referents and the connectors and then the production of inferences concerning the implicit relations between the propositions or the sentences.

In a synthetic way, the reader must, from these clues develop narrative skills in reception and production. In reception, he must learn the construction of a mental representation.

That said, the reader must translate the written code into meaningful language units which will be combined to achieve a mental and coherent representation of the text. He must sort and organize the information by memorizing the most important and 
Houssem Guedich et al., J Adv Educ Philos, Jan, 2022; 6(1): 12-23

ignore the insignificant details. The reader must therefore show a certain flexibility to build his understanding since his working memory will be heavily used but he can only process a limited amount of information. The success of the activity also depends on the reader's ability to relate the information read to his knowledge of the world, especially if he already has a reader's project or if he has defined a waiting horizon in relation to the text.

In the end, to self-regulate and question the process implemented, the presentation of these processes invites us to question the way in which the reader organizes, controls and regulates his operations since reading is a dynamic and non-linear process... The reader should use meta-comprehension or what may be called metacognition applied to comprehension.

\section{3. Popular literature and scientific tale}

In children's literature, works devoted to popular science are fairly widespread and which could be used to appeal to the imagination of young readers by conveying certain concepts and enriching their knowledge. Among these works are "educational" tales which are narrative texts intended for young readers of primary school (and even for a more advanced age). In children's literature there are, according to Donovan and Smolkin (2001), three types of literary texts intended for learning science: the documentary, the hybrid and the narrative.

The narrative text precisely is the third type of literary text for learning science. The story, in this case, presents a scientific issue as a backdrop. After studying narrative texts, Norris et al., (2005) have developed a model which presents the eight characteristics specific to this type of text and which are (i) events (something that happened), (ii) a narrator someone who tells (iii) a plot which induces in the reader an appetite for narrative (iv) taking place in the past time, (v) of a structure in the story (vi) which features characters, (vii) having an objective (a quest / goal ) (viii) and a reader (a narrated): someone who receives.

Let us recall here that scientific tales find their origin in a meeting between the world of literature, that of psychoanalysis, the scientific field and the field of didactics. Created in the purest tradition of fairy tales, their primary objective is to allow non-scientists to conveniently understand a number of natural and social phenomena. Beyond their purely playful aspect, these tales turn out to be powerful tools in the service of mediation and teaching for several reasons of which we try to make the main elements.

Combining the tradition of orality and that of transmitting knowledge, storytelling can also become a teaching tool that can be used in the classroom. Presented as described above, it can be used in different ways. Representing a transversal object par excellence since it is above all literary to become a support for scientific knowledge, it allows various approaches, depending of course on the subject with which it deals. In connection with our research, we can say that the tale makes it possible to approach in a systemic way themes such as health or the environment. The educational treatment of tales opens up possible remedies to alleviate social, health and environmental problems and plagues such as obesity, smoking, pollution. It also opens the way to questioning the origins of social differences, the systematic exploitation of the poor by the rich, etc.

\section{4. Teaching practices of reading and storytelling.}

The analysis of the effects of reading (reading) and telling (storytelling) is necessary by focusing on the study of a number of teaching activities, from fictional stories such as tales with a scientific aim and educational. These studies make it possible to analyze the effects of these two activities within the framework of the activities of environmental education clubs and to compare the understanding of the stories in question by visually impaired students. However, reading alone, regular and / or expert, is not enough to achieve comprehension of texts, which constitutes a high-level cognitive activity (Blanc, 2010; Fayol, 2013), under development among students, and which is, partially, dependent on the age of the children (attention and memorization capacities, universe of beliefs, methods of representation, etc.).

On the one hand, the reading activity is conceived as a phase of discovery of the story and rereading as a phase of memorization. In general, teachers mobilize specific methods of reading and types of textual transmission, such as adaptation, dramatization, etc. These different ways of reading bring up to date multiple interpretations of fictional stories or narratives and constitute modes of support for the comprehension activity of the students, support which testifies to the will of the teachers to make possible the comprehension of the stories.

Other teachers situate their reading activities in a zone between reading it (use of text, images, etc.) and telling it (rehearsals, oral elements, etc.), between oral and written, so that the students can rely on components of spoken language characteristic of most exchanges (intonations, repetitions, reformulations, pronunciations, phatic elements, etc.). Nevertheless, some teachers prefer to read the stories without changing the written texts and greatly mobilize the oral components by frequently telling stories. On the other hand, storytelling activities do not necessarily come under oral literature. Indeed, teachers often tell from written versions available to them. The storytelling activity then offers a sort of oral narrative recovery of a written story. 
Houssem Guedich et al., J Adv Educ Philos, Jan, 2022; 6(1): 12-23

More precisely, the teacher does not read, he speaks and his wordings express his understanding through a set of elements such as lexical reformulations, modifications of dialogues, voice mutations for the characters and intensity for announce emotions, articulations of events, repetitions of words, additions or additions of information. To summarize, we would like to point out that the different ways of reading and telling take into account, in a differentiated and complementary manner, the age of the students, their understanding of the oral or written form of language, their listening and listening skills memorization, according to the indicators listed by Legros (1988), and also the fact that the story and the characters are being constructed as specified (Fayol 1985).

\section{METHODOLOGY}

\section{1. Presentation to the public}

Regarding the study audience, the children who took part in this experience were taken care of by the Tunisian Association for the Education of Blind Children of Sfax (ATEEA) and schooled in its premises as part of a solid partnership with the Sfax Regional Education Commission 1.

According to the director of the association (A.T.E.E.A.) the majority of enrolled students come from disadvantaged backgrounds which are often characterized by financial insecurity and "social" deprivation as well as the low education of parents, we can successively classify these two characteristics according to the categorization of (Gebran, 2021) among the factors attributed to family and society contributing to the high rate of learning loss in learning subjects.

On the other hand, the repeated absenteeism of the learners and their inability to adapt to the school environment which, according to the same author, constitute factors linked to the learner having an additional effect on the loss of learning alongside the factors linked to the education system and the school (such as the low efficiency of teaching methods, the insufficiency and non-conformity of the programs with the interests and needs of the students and their characteristics ...). At the time of this research (the 2017-2018 school year), the fifth category of factors defined by Jebran (2021), i.e., factors attributed to emergencies (disruption and illnesses, etc.) have a very limited additional effect on the loss of learning in the learning subjects of our sample.

Fourteen students from four classes (two different degrees) were mixed so as to reconstitute two comparable groups; on the one hand they have almost the same number of students belonging to the second degree (3rd and 4th) and to the third degree (5th and 6th), on the other hand according to the gender so as to keep, the same number of girls per group, in addition the two groups of the samples include the same number of students with precocious blindness (or blindness from birth). In the end, one of the two groups was accidentally named the story reading group and the other the storytelling group.

\section{2. Experimentation}

\section{2. 1. Didactic tools used (narrative texts)}

The tools used in the present study are illustrated educational stories that would allow a practical and active approach with a group of visually impaired students to a given theme such as the themes of environmental health, energy, environment, biodiversity, climate change, and sustainable development in order to raise awareness.

The stories used in this research were selected by a panel. They were evaluated on the basis of the following criteria: the stories should be short, simple and should be of interest to a child of the target age (between 8-11 years old), each story should have attractive illustrations (even if it is targets a population of visually impaired and blind children), deal with topics related to the environment and environmental health and, above all, content that had to be suitable for both reading aloud and storytelling. Let us first of all remember that the selection to be analyzed and validated at the end of the application of an exhaustive analysis grid bringing together the material, iconographic, narrative and ideological aspects to estimate the value of these educational tools and subsequently extract from each story the knowledge and skills that will be the subject of our knowledge / understanding tests.

The stories (of foreign origin; Swiss and American) $\left[{ }^{6},{ }^{7}\right]$ have been translated into Arabic by translation specialists then checked and adapted with the Tunisian context by researchers and teachers in the scientific fields that make up each story to ensure preservation of scientific messages and integrity of scientific content. As an example, in the tale "They are going to put an antenna on my roof" the sentence "Public protection service, hello. What can I do for you?" Has been replaced by the following sentence "National Frequencies Agency, hello. What can I do for you?" Considering that the ANF is the only public Tunisian company which ensures the technical control of the frequencies and which is the equivalent of the service which appears in the original account and which can inform us on the questions of the customer.

In the same story, the sentence "You know, the safety margins applied in Switzerland are much more cautious than elsewhere in Europe" has undergone

\footnotetext{
https://www.energie-

environnement.ch/maison/chambre/contes-

pedagogiques

${ }^{7}$ www.science a-z.com
} 
Houssem Guedich et al., J Adv Educ Philos, Jan, 2022; 6(1): 12-23

some modification to adapt it to the local context "You know, the safety margins applied in Tunisia are much more cautious than elsewhere in Africa or in Europe". All these adaptations were necessary to accommodate the stories to our study population (Tunisian primary school students aged 8 to 11 ).

The breakdown and distribution of the stories over the six sessions of our experience for our sample, as well as their themes are shown in the table below.

Table 1: Breakdown of stories about the sessions

\begin{tabular}{|l|l|l|}
\hline & Theme of the session & Number of words \\
\hline «Mr. Redfish's jar » & Greenhouse effect & $\mathbf{8 3 1}$ \\
\hline «Barbataz's arm » & Poaching \& protected species & $\mathbf{9 1 9}$ \\
\hline «The messenger of the trout & Micropollutants & $\mathbf{1 0 1 5}$ \\
\hline "They will put an antenna on my roof” & Electromagnetic pollution & $\mathbf{1 0 3 5}$ \\
\hline « Molly Q's Adventure » & Water cycle & $\mathbf{1 2 3 3}$ \\
\hline «The spell of mandarins » & Obesity and sedentary lifestyle & $\mathbf{1 5 1 3}$ \\
\hline
\end{tabular}

\section{2. 2. Knowledge / comprehension tests}

To assess the effectiveness of our didactic tool "the story" in the learning of certain knowledge related to environmental education and to try to confirm whether this tool allows the learners to understand this different knowledge, it is necessary to cross-referencing it with a means of analyzing the targeted learning. To do this, we will limit ourselves according to Bloom's taxonomy (1956) to the first and second level of acquisition, which are respectively knowledge (memorization of information) and comprehension.

From the stories, and following the analysis of the textual data, we constructed statements allowing their understanding to be assessed. These statements relate to the knowledge (knowledge, skills (know-how) and attitude) related to the theme of each tale. The statements (propositions) were then categorized into punctual and / or global information, into information linked by a non-causal logical link (part-whole relation) and into information linked by a causal link (Marin, Crinon et al., 2007).

The propositions of the "specific or global information" type, are respectively information taken from one place or several places in the text, which describe states, actions or events, isolated and independent of the causal chain which makes it possible to account for the situation. logical and explanatory relationship of the resulting state or event. Information of the "part-whole" type describes a macro-event or a macro-action in generic form and therefore without explanation of causality. Causally linked information explains information inserted in a causal chain explaining the state or event. In the tale "the messenger of the trout" the sentence "But they have difficulty digesting artificial substances" includes, according to the model of Dijk and Kintsch (1978, 1983), several propositions, one of these propositions to is the subject of a statement (in appendix A there is an example of a statement for this situational dimension) in the "one-off and global information" of the knowledge test relating to the theme of the third session "Micropollutants".
On the other hand, the sentence "The chemist explained to me that each of us unknowingly pours thousands of artificial substances into the water. It is found in most of the products we use at home to do laundry and dishes, to shower, to heal our body, to put on make-up, to clean the household or his vehicle, or even to tinker ..." presents more than eight semantic propositions of the part-whole type, where the generic term "artificial substances" is exemplified by a certain number of its specifics. Four of these propositions were the subject of statements in the information linked by a non-causal logical link (part-whole) of the knowledge test relating to the same theme "Micropollutants" to assess the student's ability to infer a meronymic relation (distinguish the categories of the specific and the generic) (in appendix A is an example of a statement for this situational dimension).

A sentence such as "Our problems are related, with the strange emanations that are continually arriving in our lake". is distributed into expanded semantic propositions in addition to four causal semantic propositions insofar as there is a causal relationship between the two members of the assertion (in appendix $\mathrm{A}$ is an example statement for this situational dimension). It was noted that sometimes these statements (information) were not taken directly from the text so they may correspond to inferences or paraphrases.

After categorization, we developed four statements per situational dimension for each of the six tales (two statements gave rise to the response "it's true" and the two others to the response "it's false"), i.e., twelve statements per story ( 6 true statements, 6 false statements). Thus, on the basis of the information provided in each tale, we constructed four statements on specific or global information, four statements on information linked by a non-causal logical link (partwhole or meronymic relationship) and four concerned the causal links between the various events reported.

The organization of the tests is distributed according to the descriptive table below. 
Houssem Guedich et al., J Adv Educ Philos, Jan, 2022; 6(1): 12-23

Table 2: Organization and content of knowledge / comprehension tests

\begin{tabular}{|c|c|c|}
\hline Proposal number & Categories of Proposals (statements) & Response values \\
\hline 1 & \multirow[t]{4}{*}{ One-off and / or global information } & \\
\hline 2 & & \\
\hline 3 & & \\
\hline 4 & & \\
\hline 5 & \multirow{4}{*}{$\begin{array}{l}\text { Information linked by a logical non-causal link } \\
\quad \text { (Part-whole } \\
\text { relationships) }\end{array}$} & \\
\hline 6 & & \\
\hline 7 & & \\
\hline 8 & & \\
\hline 9 & \multirow{4}{*}{$\begin{array}{c}\text { Information linked by a causal link } \\
\text { (Causal Relationship) }\end{array}$} & \\
\hline 10 & & \\
\hline 11 & & \\
\hline 12 & & \\
\hline
\end{tabular}

\section{2. 3. Course of the session}

Our experimentation was spread over three moments, namely:

- A pre-test: it is a knowledge test which includes questions with simple answers of the type (true/false), it makes it possible to measure the preliminary knowledge of the subjects. This test evokes by its statements the fundamental notions relating to the theme of the day which appear in the story. These statements focus on the knowledge, skills and attitude related to the theme of each story to determine the initial level of environmental awareness of each student.

- Tell the story (recitation) by the teaching practice of reading or storytelling according to the groups of students; before the start of each session, the participants are led by the researcher and the assistant who accompany them from their classrooms to the library (computer room at the same time) of the school, it is in this place where takes place the environmental education club through "scientific" stories.

At the start of each session (storytelling session), the facilitator will ask each group a few questions. These questions aim to stimulate students' attention and engage critical thinking skills. For example, before starting with the tale "they are going to put an antenna on my roof" which includes new concepts such as "electromagnetic", "field", "microwave", the researcher proceeded to an explanation of the terms on which are based our story of the day so that when passing these words, the learner will have no difficulty understanding, so as not to miss the rest.

Then, the story of the day will be read or actively told (depending on the group present) by the researcher in charge of the task. During the presentation and to encourage the students to be active rather than passive listeners they will have the opportunity to interact with the storyteller / reader who sometimes stops and asks them to predict the next part of the story or respond to a question to ensure their attention. Each of the two teaching practices lasts approximately 15 to 25 minutes (depending on the size of the story and the technique used). The students of the first group who have finished the recitation session are returned to their classes to answer the final test and the other students of the reading group take their places,

- A post-test: the same initial knowledge test (Using the same concepts mentioned in the preliminary test). We start again with the initial test which includes the twelve statements. As with the initial test, students will answer in Braille (on special white paper). From the second week of the experiment and in order to motivate them, our candidates are informed at the beginning of each storytelling or reading session of their collective progress recorded (at the previous post-test) during the last session of the knowledge / understanding in order to motivate them (feedback on overall performance).

Progress $=$ (number of correct post-test answers - number of correct pre-test answers).

\section{2. 4. Collection of responses and analysis}

The students answered in Braille all the questions of the 6 tests. At the end of each session, the students' copies (knowledge tests) are collected by the assistant in charge of accompanying and teaching the students to translate them into text (Arabic).

We managed to collect all the answers to the questions asked in the knowledge / comprehension tests. For these closed questions, the quality of the information is judged on the basis of the truth value of the propositions which support this information, so we have assigned " 1 " to the correct answer and " 0 " to the wrong answer. there were no non-answers, so any " 0 " corresponds to a wrong answer. The results were processed with: Statistica 12 software (StatSoft, France). It should be noted that the main objective of this study was to assess the progress of the students (in the reading group and in the storytelling group) estimated by their performance in the pre-tests and posttests. As for the hypotheses, they are as follows: 
Houssem Guedich et al., J Adv Educ Philos, Jan, 2022; 6(1): 12-23

On the one hand, H1. The teaching practice of telling (storytelling) would be more beneficial in terms of knowledge acquisition (carried out between a pre-test and a post-test) than the teaching practice of reading for visually impaired students integrating into the A.T.E.E.A of Sfax.

On the other hand, H2. The teaching practice of storytelling would better help the visually impaired listeners in our sample to succeed in their responses to causally related information (to make causal inferences).

\section{RESULTS}

For each of the pre-test and post-test questions, a correction grid was developed and a score out of 12 points was calculated. The primary endpoint was the comparison of the mean scores for all of the pre-tests with those obtained for all of the post-tests, using a paired t-test. The analysis then focused on the comparison of the mean obtained at the pre-test and at the post-test per session (paired t-test).

The assessment of knowledge using a simple answer questionnaire (closed for example) or by multiple choice questions has several limitations (Veloski et al., 1999). But the administration of a test with identical questions before a (training) (pre-test) and after (training) (post-test) makes it possible to assess an immediate improvement in the knowledge acquired, even if we cannot judge by advance the transferability of the learning assessed (Llorca, 2003). The administration of such a pre-test and post-test within our environmental education club sessions further allows to assess the initial knowledge and the recalled and inferred knowledge of the visually impaired students of the A.T.E.E.A. following the oral presentation of a scientific educational story.

\section{1. Pre-test and post-tests: global analysis in the two groups}

The comparison of the mean scores for all the pre-tests with that obtained by all the post-tests (primary endpoint) for the two groups shows a significant difference with respectively an average of 35 \pm 8.06 and $61.29 \pm 8.2$ points out of $72(\mathrm{p}<0.001)$ for the reading group and $36.57 \pm 9.66$ and $67.57 \pm 3.21$ points out of $72(\mathrm{p}<0.001)$ for the storytelling group (Table 3).

The comparison of the rate of progression according to the groups (reading or storytelling) does not show a significant practical consequence. In fact, we recorded an average relative gain of $75.1 \%$ for the reading group and $84.77 \%$ for the storytelling group (Table 3).

Table 3: Average of the scores, standard deviation, absolute gain $(\Delta)$ and relative gain $(\Delta \%)$ by group (Reading / storytelling) for all six sessions in the pre-tests and post-tests.

\begin{tabular}{|l|l|l|l|l|}
\hline & Pre-tests (Before) & Post-tests (After) & $\Delta(\Delta \%)$ & Gain \\
\cline { 2 - 4 } & $\begin{array}{l}\text { Score out of 72 points } \\
\text { (Standard deviation) }\end{array}$ & $\begin{array}{l}\text { Score out of 72 points } \\
\text { (Standard deviation) }\end{array}$ & Absolute gain $(\Delta)$ & $\begin{array}{l}\text { Gain } \\
\text { relative }(\Delta \%)\end{array}$ \\
\hline Reading Group $(\mathrm{N}=7)$ & $\begin{array}{l}\mathbf{3 5} \\
( \pm 8.06)\end{array}$ & $\begin{array}{l}\mathbf{6 1 . 2 9} * * * \\
( \pm 8.2)\end{array}$ & 26.29 & $75.1 \%$ \\
& $\begin{array}{l}\mathbf{6 7 . 5 7} * * * \\
( \pm 3.21)\end{array}$ & 31 & $84.77 \%$ \\
\hline Storytelling Group $(\mathrm{N}=7)$ & $\begin{array}{l}\mathbf{3 6 . 5 7} \\
( \pm 9.66)\end{array}$ & & \\
\hline & $* * *:$ significant difference compared to Before at $\mathrm{p}<0.001$ \\
\hline
\end{tabular}

\section{2. Type of proposals recalled according to the groups}

The comparison of the rate of progress made by the two groups (reading and storytelling) for the same types of propositions in terms of average relative gain $(\Delta \%)$ shows a significant progression of the storytelling group compared to the reading group for the information linked by a causal link ( $86 \%$ vs $121 \%$ ) (p $<0.05$ ). For the two other propositions ("One-off and global information" and "information linked by a noncausal logical link (part-whole relationship)"), the comparison of the rate of progression according to teaching practice has no significant practical consequence (Figure 2).

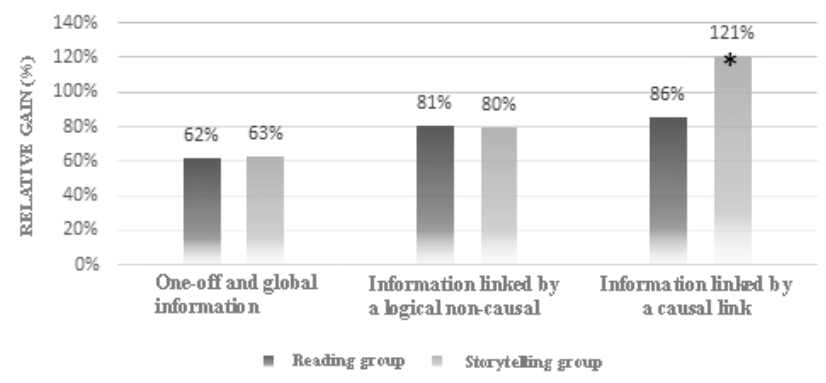

Figure 2: Progression in terms of the correct answers to each type of information (proposals) in the reading group and the storytelling group 
Houssem Guedich et al., J Adv Educ Philos, Jan, 2022; 6(1): 12-23

In the same way, the comparison of the average of the scores for all the pre-tests with those obtained by all the post-tests of the responses to the four (4) propositions which concern the information "linked by a causal link. », Presents a significant difference for the two groups, that is to say the reading group and the storytelling group, with respectively an average of $10 \pm$ 3.16 and $18.57 \pm 4.2$ points out of $24(p<0.001)$ for the reading group and $10.14 \pm 3.53$ and $22.43 \pm 1.9$ points out of $24(\mathrm{p}<0.001)$ for the storytelling group (Table 4).

Table 4: Average of the scores, standard deviation, absolute gain $(\Delta)$ and relative gain $(\Delta \%)$ for the information with causal relation by group (Reading / storytelling) for all six sessions at the pre-tests and post-tests

\begin{tabular}{|l|l|l|l|l|}
\hline & Pre-tests (Before) & Post-tests (After) & $\Delta \mathbf{( \Delta \% )}$ \\
\cline { 2 - 5 } & $\begin{array}{l}\text { Score out of 24 points } \\
\text { (Standard deviation) }\end{array}$ & $\begin{array}{l}\text { Score out of 24 points } \\
\text { (Standard deviation) }\end{array}$ & Absolute gain $(\Delta)$ & $\begin{array}{l}\text { Gain } \\
\text { relative }(\Delta \%)\end{array}$ \\
\hline Reading Group $(\mathrm{N}=7)$ & $\begin{array}{l}\mathbf{1 0} \\
( \pm 3.16)\end{array}$ & $\begin{array}{l}\mathbf{1 8 . 5 7} * * * \\
( \pm 4.2)\end{array}$ & 8.57 & $85.71 \%$ \\
\hline Storytelling Group $(\mathrm{N}=7)$ & $\begin{array}{l}\mathbf{1 0 . 1 4} \\
( \pm 3.53)\end{array}$ & $\begin{array}{l}\mathbf{2 2 . 4 3} * * * \# \\
( \pm 1.9)\end{array}$ & 12.29 & $\mathbf{1 2 1 . 1 3 \%}$ \\
\hline
\end{tabular}

\section{DISCUSSION}

Studies have shown that the processes of comprehension in general cannot be dissociated from those of memory. Indeed, memory and comprehension are two fundamentally linked activities (Blanc \& Brouillet, 2003). The process of comprehension is not limited to just reading what is written. Indeed, several studies in this direction have shown that the cognitive processes of reading comprehension are the same ones involved in oral comprehension (Just \& Carpenter, 1987; Perfetti 1985). In this perspective, and following this approach, we will refer in part in our discussion to the common cognitive mechanisms involved in the understanding of the texts, summarized and presented by Bianco (2016).

The effect of reciting stories (by story reading and by storytelling) on the immediate knowledge acquisition of visually impaired students

The progression in terms of the average of the correct answers for the two groups (reading / storytelling) is clearly significant in our sample. But, the comparison between the rate of progress made by the storytelling group and the rate of progress made by the reading group does not show a significant difference between the two teaching practices. From these same results and within the framework of the first hypothesis (H1), we believe that the listeners of the experimental group of our sample did not know how to benefit from the contribution of the teaching practice of storytelling by all its specific modalities of dramatization. (Oral lines, repetitions, reformulations, accentuation ...), of adding and adding information. Consequently, the first hypothesis (H1) of our study is not validated.

\section{Effect of the teaching practice of storytelling on the mean of true causal propositions}

Let us start by recalling that no significant progression (revealed by the $\Delta \%$ ) of either of the two teaching practices was found for the three propositions together (all 12 propositions), which required to analyze the results by type of information (type of proposal), as well as the comparison of the progress made in the two groups (reading / storytelling) at the level of each of the three types of information (local and global information; part-whole information; information linked by a causal link) shows, as we have assumed for the second hypothesis (H2), a significant progression of the storytelling group compared to the reading group in terms of responses to information linked by a causal link with an average relative gain of $121.13 \%(p<0.5)$.

The students of the experimental group with whom we used the teaching practice of storytelling (telling) and who benefited from its modalities (mentioned above) made significant progress in terms of their correct answers to the information offered than those of the other group with whom we used simple reading.

We believe that the modalities of the storytelling allow listeners to build the coherence of the narrative text told. Indeed, the addition of information (additional notes) allowed to create causal links between the information present in the text of each of the six stories; this explains the success of the experimental group (storytelling) over the simple reading group in their responses to information linked by a causal link.

At this stage of the analysis, we believe that the provision of some explanation of the non-explicit information in the text seems to promote coherent construction in the listener. Consequently, the activity of storytelling and the acquisition of knowledge appear to be closely linked.

We believe that the rhythm and the atmosphere of the storytelling make the student listener at ease which allows him to mobilize his knowledge, at different levels starting with knowledge about language, text and his knowledge of the world. Indeed, the practice of storytelling catalyzes this "solicitation mechanism" by its different modalities such as adding information, lexical reformulations (Goffin, 1993) 
Houssem Guedich et al., J Adv Educ Philos, Jan, 2022; 6(1): 12-23

which are added to knowledge about language and text as well as to the author's knowledge to elucidate the information conveyed by the various narrative texts offered.

We believe that the additions of information referring to the knowledge of the world evoked by the narrative text of the story help the listeners of the group to produce causal inferences and thus respond appropriately to information of this type. The information added during storytelling helps to develop in the listener skills concerning the processing of continuous speech and helps to infer the implicit relationships between clauses or sentences, these inferences are therefore based on using "added information" as well. only on the listener's knowledge and / or that of the text.

We think that the adaptations which constitute the storytelling activity seem to help the students to grasp the implicit meanings in particular by the use of the oral markers, which especially accentuate the causeand-effect relationships. Thus, implementing the storytelling activity offers a contextualization and a concretization of the meanings of the story for implicit parts (cause and effect link, coexistence of events, temporality ...). Likewise, the use of multiple and heterogeneous signs (intonation, commentary, etc.) within this activity encourages listeners (students) to construct meanings.

We believe that the recitation of stories through the practice of reading or storytelling protects the student (listener) from any ambiguity or failure related to his ability to identify words when decoding the text if it has been read (Gaonach and Fayol, 2003). The recitation of stories and especially via the storytelling technique through some of its modalities (intonation, pronunciation, repetition of words ...) helps to succeed in understanding the text and it somehow bypasses the skill of identifying words in novice students, thus, begin understanding in "safe mode".

Ultimately, we think that the different modalities of storytelling that we have just listed their effects on the improvement of the correct answers to the propositions in relation to the comprehension of the six narrative texts, come to compensate and / or remedy the missing or defective cognitive structures and mechanisms (through learning loss) in visually impaired learners at the level of the 4 categories of skills cited in the diagram by Bianco (2016), These skills which are often requested simultaneously are: the ability to identify words, the knowledge stored in memory (on language /the text / that concerning the world), the general cognitive efficiency of individuals (metacognition applied to comprehension) and the skills specific to the continuous speech processing.
It should be noted here that these results are, moreover, reconcilable with those given by Goffin, (1993) who revealed in a similar study that lexical reformulation acts vigorously on comprehension in the youngest students, whose lexical capital is not consistent enough. Likewise, these explanations can be associated with the results obtained by McNamara D.; Floyd R.; Best R. \& Louwerse M. (2004) in research carried out with $3^{\text {rd }}$ grade elementary school students, which shows that understanding of a scientific text is first affected by the knowledge of the subject's world, while their understanding of the story is tied first to their deciphering skills.

Finally, we believe that even visually impaired students with certain cognitive disorders could develop the pattern of an evolving understanding of the narrative texts proposed during the sessions aimed at the appropriation of certain scientific concepts. In addition, the common thread that constitutes the story facilitates memorization and constitutes a cognitive load to offer content requiring special attention. We also specify that the plot, the challenge, the situation in which the hero finds himself, and from which he must emerge victorious, promote the understanding of the scientific message by students in general and more especially those with disabilities such as visually impaired people.

Moreover, the story does not only grab the attention of the recipients but on the contrary, it stimulates the listener or the reader to really understand, in order to remain at the same level of sublimation as the hero of the story told (Pellaud et al., 2007). In the end, the use of "scientific" stories with our study population (visually impaired students) leads us to use these two activities of reading and telling in environmental education club class in order to understand how these two types of story recitation can participate in the educational mediation of certain scientific and environmental concepts to a particular audience made up of young people with visual impairments.

\section{CONCLUSION}

At the end of this article, we can say that understanding a text requires the construction of a mental representation of the situation described by this text. The teaching practice of storytelling used to transmit the narrative text (scientific story) would help to optimize this mental representation in visually impaired students suffering from learning loss. The support on knowledge of the world and on inferential activities via the different modalities of storytelling practice support and enrich this construction.

This research is part of the work of a doctoral thesis, which focuses on the effect of certain popular science literature presented orally in an environmental education club on the acquisition of certain knowledge, 
Houssem Guedich et al., J Adv Educ Philos, Jan, 2022; 6(1): 12-23

in a specific public constituted visually impaired people.

In the end and in view of the analysis of the results and their discussion, we found that the different methods of storytelling prove to be effective with elementary school students suffering from a visual impairment, especially when they are new to reading to remedy to "learning loss". Stories are excellent sources and tools to help teachers explain science concepts to students and overcome some learning loss. These encouraging results invite us to use stories and the practice of storytelling in school and extra-curricular contexts (clubs, sequences recorded on educational platforms, etc.) in order to remedy the learning loss in visually impaired students in particular and in other students in general.

The impact of the COVID-19 crisis on learning is of particular concern, particularly in primary education, as basic skills are the cornerstone of all education, and mastering these skills is essential to grasp the lifelong opportunities. Although learning loss is inevitable, it can be reduced with appropriate decision-making and well-designed system-wide interventions, including teachers, families and all other links in the educational chain.

To support the development of students, it is essential to continue to provide them with a comprehensive education and not to place academic performance at the forefront. Encouraging social and emotional activities, such as using educational stories to impart scientific knowledge, so that students regain their motivation and involvement in learning, could help them adapt in a positive way to new school tasks. Schools, especially those meant to support specific audiences, must demonstrate that they can provide the essential support that children and young people need in these difficult times.

Annex:

\begin{tabular}{|l|}
\hline Dimension: One-off and / or global information \\
\hline Bacteria easily break down synthetic materials. (False) \\
\hline $\begin{array}{l}\text { Dimension: Information linked by a logical non-causal link } \\
\text { (Part-whole or meronymic relationships) }\end{array}$ \\
\hline Among the sources of micropollutants are perfumed products. (True) \\
\hline $\begin{array}{l}\text { Dimension: Information linked by a causal link } \\
\text { (Causal Relationship) }\end{array}$ \\
\hline Micropollutants in lake water cause reproductive problems in salmon. (True) \\
\hline
\end{tabular}

\section{BIBLIOGRAPHY}

- Abdel-Wadoud, M. (2020). The concept of educational loss and its causes... What is educational loss? The comprehensive Arabic encyclopedia. [in Arabic] Available on the Internet: https://www.mosoah.com/education-andcareer/educational/wastage-educational

- Best, R., Floyd, R. G., \& McNamara, D. S. (2004, April). Understanding the fourth-grade slump: Comprehension difficulties as a function of reader skills and text genre. In 85th Annual Meeting of the American Educational Research Association.

- Blanc, N. (2010). Understanding tales between 5 and 7 years old: What representation of emotional information? Canadian Journal of Experimental Psychology / Revue canadienne de psychologie experientale, 64(4), 256.

- Blanc, N., \& Brouillet, D. (2003). Memory and comprehension: Read to understand, Paris: Éditions InPress.

- Bloom, B. S. (1956). Taxonomy of educational objectives. Flight. 1: Cognitive domain. New York: McKay, 20(24), 1.

- Eco, U. (1985). Lector in fabula. The role of the reader. Trans. Myriem Bouzaher. Paris: Grasset.

- Fayol, M. (2013). The acquisition of writing. Paris: PUF, coll. "What do I know? "
- Fayol, M. (1985). The story and its construction. Neuchâtel: Delachaux-Niestlé

- Gaonach, D., \& Fayol, M. (2003). Helping students to understand, Paris: Hachette.

- Gibran, W. (2020). Learning Loss: What is it? How do we work to reduce it? [in Arabic] Available on the Internet: https://www.teachercc.org/uploads/articles/7208c8 2f5f295e6cce79809a428f9440.pdf

- Girardet, P. (2018). The construction of the comprehension of narrative texts by students with cognitive disorders: research carried out within localized units for educational inclusion, University of Lyon.

- Issa, A. (2020). What is the educational loss? [in Arabic] Available on the Internet: https://www.teachercc.org/uploads/articles/7208c8 2f5f295e6cce79809a428f9440.pdf

- Just, M. A., \& Carpenter, P. A. (1987). The psychology of reading and language comprehension. Allyn \& Bacon.

- Kintsch, W., \& Van Dijk, T. A. (1978). Toward a model of text comprehension and production. Psychological review, 85(5), pp. 363-378.

- Legros, D. (1988). Role of a dramatization process on the memorization of a story. The Psychological Year, 88(2), 197-214. 
- Llorca, G. (2003). Evaluation of the immediate educational effectiveness of two classic methods in continuing medical education. Medical education, 4(1), 26-32.

- Marin, B., Crinon, J., Legros, D., \& Avel, P. (2007). Reading a scientific documentary text: what obstacles, what aids to understanding? French review of pedagogy. Educational research, (160), 119-131.

- $\quad$ Meyer, F., Meissel, K., \& McNaughton, S. (2017). Patterns of literacy learning in German primary schools over the summer and the influence of home literacy practices. Journal of Research in Reading, 40(3), 233-253.

- Norris, S. P., Guilbert, S. M., Smith, M. L., Hakimelahi, S., \& Phillips, L. M. (2005). A theoretical framework for narrative explanation in science. Science Education, 89(4), pp. 535-563.
- Pellaud, F., Eastes, R. E., Sené, N., \& Collet, B. (2007). Take science as a story. Revue Grand N, Nantes.

- Perfetti, C. A. (1985). Reading ability. London, Oxford university Press.

- UNESCO. Education: From disruption to recovery [Online]. 2020. Available on the Internet: https://en.unesco.org/covid19/educationresponse. [This article is available in French under the title Education: from the closure of schools to the recovery.]

- Van Dijk, T. A., \& Kintsch, W. (1983). Strategies of discourse comprehension.

- Veloski, J. J., Rabinowitz, H. K., Robeson, M. R., \& Young, P. R. (1999). Patients don't present with five choices: an alternative to multiple-choice tests in assessing physicians' competence. Academic medicine: journal of the Association of American Medical Colleges, 74(5), 539-546. 